\title{
A IDEIA DE CONSTITUIÇÃO COMO ORIENTAÇÃO HISTÓRICA: CONTRAPOSIÇÕES DA COGNIÇÃO SITUADA NA RACIONALIDADE EPISTEMOLÓGICA DA HISTÓRIA AO PROJETO DE LEI 6.840
}

Rafael de Jesus Andrade de Almeida²

- Enviado em 31/01/2016

- Aprovado em 14/02/2016

Está no projeto de lei 6.840 , no seu artigo $1^{\circ}$, que ao reformular a redação do artigo 36 propõe no parágrafo $3^{\circ}$, inciso VII, a inclusão como tema transversal de "Noções básicas de Constituição Federal (BRASIL, 2013)." O uso pedagógico da Constituição à orientação da vida prática dos jovens certamente não é uma novidade. Possivelmente o exemplo mais conhecido tenha sido o livro O Estado Nacional e a Constituição de novembro de 1937: para uso da juventude, do desembargador Álvaro Bittencourt Berford, publicado em 1944 e patrocinado pelo Departamento de Imprensa e Propaganda, mais conhecido como DIP (BERFORD, 1944).

Porém, do ponto de vista do ordenamento jurídico, é a primeira vez que poderemos ter numa Lei de Diretrizes e Bases da Educação Nacional uma referência clara ao estudo da Constituição Federal como tema fundamental à formação intelectual dos jovens brasileiros.

A relação entre Constituição e Lei de Diretrizes e Bases da Educação Nacional precisa ser uma relação de mão dupla. Por um lado, cabe à Carta Magna determinar a elaboração da LDB, por

\footnotetext{
${ }^{1}$ Altera a Lei no 9.394, de 20 de dezembro de 1996, que estabelece as diretrizes e bases da educação nacional, para instituir a jornada em tempo integral no ensino médio, dispor sobre a organização dos currículos do ensino médio em áreas do conhecimento e dá outras providências.
}

${ }^{2}$ Professor de História do Colégio Estadual Professor Júlio Szymanski, Araucária-PR e Coordenador de Ensino de História da Prefeitura Municipal de Araucária. Endereço eletrônico: aprenderhistoria@yahoo.com.br 
outro lado, cabe à LDB se responsabilizar de forma clara com o trato do tema Constituição, nos seus aspectos históricos, filosóficos e sociológicos.

O mérito do PL 6.840 e do livro do Dr. Álvaro Berford está na preocupação em se fazer conhecer algo sobre a Constituição em vigor. Provavelmente devido a percepção de que os brasileiros não sabem muita coisa sobre a nossa Carta Magna. Essa percepção tem mais de um século. Os exemplos históricos são muitos, a título de constructo explicativo vamos nos referir a dois casos significativos.

Em 21 de fevereiro de 1914, faltando três dias para o aniversário de 23 anos da Constituição de 1891, que naquele ano cairia em plena terça-feira de carnaval, a revista $O$ Malho publicou uma charge do caricaturista e chargista Aryosto Duncan onde Zé Povo travestido de Pierrot conversa com a tristonha aniversariante. Vale a pena conferir:

“Zé Povo: - Então rapariga! Hoje é dia dos teus annos. Não te fantazias?...

Constituição: - Para quê? Ninguem me conhece..." (DUNCAN, 1914)

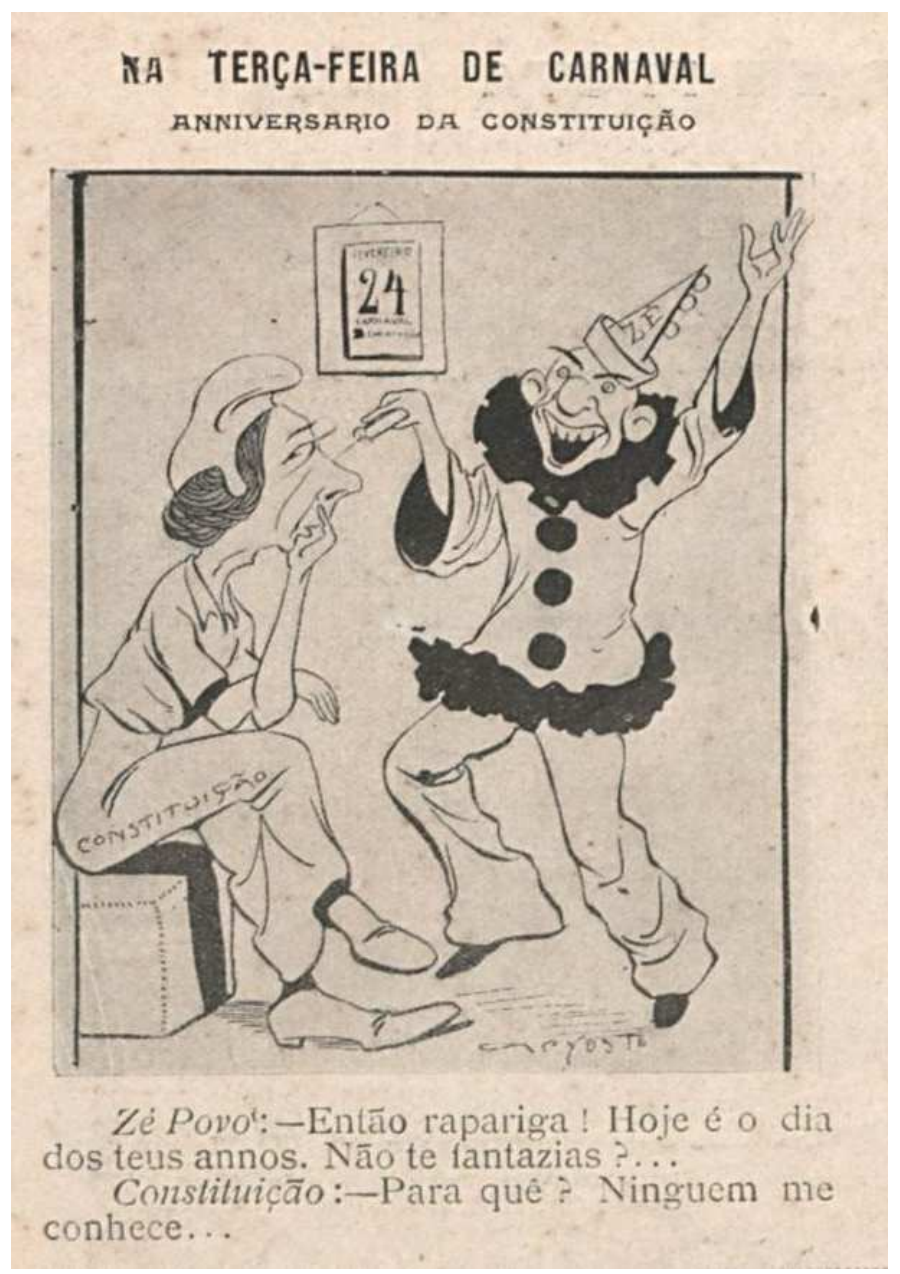

O Malho, 21/01/1914 
Mais de noventa e nove anos depois, em 5 de outubro de 2013, no exato dia em que a Constituição Cidadã completava 25 anos, a revista Veja publicava na sua versão eletrônica a seguinte avaliação sobre a nossa Carta Magna:

\begin{abstract}
Não há dúvida de que a democracia avançou no Brasil no último quarto de século e de que a Constituição teve um papel essencial nesse processo. Mas é significativo que na miríade de cartazes levados às ruas durante as manifestações de junho, e na enxurrada de mensagens postadas nas redes sociais, a Carta raramente tenha sido mencionada como um ponto de referência simbólico. Quando ela se tornou assunto, foi de modo negativo: em resposta àqueles que expressavam na rua o seu repúdio à corrupção e à classe política, o governo sugeriu, de maneira funesta, que se reformasse o sistema político por meio de uma "Constituinte específica". Entre o esquecimento dos manifestantes e o perigoso arroubo do Executivo, fica claro que a Constituição promulgada em 5 de outubro de 1988 não desfruta, em seu $25^{\circ}$ aniversário, da aura quase sagrada de que se reveste, por exemplo, a Carta dos Estados Unidos (CASTRO, 2013, p.99).
\end{abstract}

Entre uma publicação e outra, em menos de um século, vivemos sob a égide de seis Constituições. Tivemos Constituições para todos os gostos. Essas mudanças vinham a reboque dos períodos de instabilidade política que nos afligia. E, em grande parte, podemos afirmar com convicção de que a falta de uma LDB que trouxesse no seu âmago a preocupação com a Educação Constitucional contribuiu, e muito, para que vivêssemos tantos percalços políticos.

Em termos constitucionais, a ideia de uma Lei de Diretrizes e Bases da Educação foi citada pela primeira vez na Constituição de 1934, no seu artigo 5 , inciso XIV, que estabelecia claramente que competia privativamente à União traçar as Diretrizes da Educação Nacional (BRASIL, 1934). A Polaca de 1937 também se comprometeu em criar uma LDB, nos seus artigos 15 e 16, incisos IX e XXIV, respectivamente (BRASIL, 1937). O acirramento ideológico dos anos 30 não foram auspiciosos à gestação daquela que seria a nossa primeira LDB.

Somente em 1961 foi publicada a nossa primeira Lei de Diretrizes e Bases, após mais de treze anos de intensos debates protagonizados pelos defensores dos interesses da escola pública, das escolas particulares e da Igreja Católica, cumprindo finalmente o ordenamento previsto na Carta de 1946, artigo $5^{\circ}$, inciso XV, alínea $d$ (BRASIL, 1946; 1961).

Os anos 60, infelizmente, não foram melhores à efetivação de uma sociedade democrática. Sete anos após o golpe, em agosto de 1971, era sancionada a Lei 5.692, eivada pelo aparato repressivo do AI-5 e a emenda constitucional $\mathrm{n}^{\circ} 1$ de 17 de outubro de 1969, em cumprimento ao 
ordenamento constitucional do artigo $8^{\circ}$, inciso XVII, alínea $q$ (RIBEIRO, 128-152; BRASIL, 1967; 1968; 1969).

A atual LDB é resultado de um longo debate, foram mais de sete anos, entre a promulgação da Constituição Cidadã em 5 de outubro de 1988 e a publicação da Lei no 9.394 de 20 de dezembro de 1996. No mesmo dia em que a Lei 4.024 completaria 35 anos (CARNEIRO, 2014). Fica cumprido o estabelecido pelo artigo 22, inciso XXIV da Constituição da República Federativa do Brasil (BRASIL, 1988).

Acontece que nem as Leis de Diretrizes e Bases anteriores faziam referência clara ao estudo de aspectos do nosso ordenamento Constitucional, nem a redação da atual LDB o faz. Nas Lei de Diretrizes e Bases a ideia de Constituição Federal aparece sempre vinculada a duas questões: ordenamento original da própria LDB e financiamento do ensino. Nunca como algo a ser conhecido. Ao pensarmos que a atual Lei de Diretrizes e Bases traça orientações sobre o trato de temas como a educação ambiental, os direitos humanos e a história e cultura de afrodescendentes e indígenas do país, ficamos nos questionando: como deixamos em aberto tamanha lacuna?

Conhecer a historicidade da Constituição Federal é conditio sine qua non para o exercício pleno da cidadania. A aprendizagem histórica sobre o constitucionalismo é fundamental para a efetivação de uma sociedade humanista e democrática, por produzir instrumentos de orientação temporal da vida prática dos jovens na persecução incansável do respeito aos direitos humanos. De acordo com o historiador e filósofo Jörn Rüsen (2012, p. 195-6)

A experiência histórica com os direitos humanos e civis só pode conduzir, como potencial de aprendizagem, ao desenvolvimento de competências normativas, compreensões históricas, orientações e construções de identidade se for negociada em um processo de aprendizado que possa fazer a ponte entre a situação subjetiva de alunos e alunas e a prescrição objetiva de princípios constitucionais.

No entanto, não é isso que temos proposto no PL 6.840. Em termos didáticos a proposta de “noções básicas de Constituição" não difere muito do livro do Sr. Álvaro Berford. Do ponto de vista da Didática da História a fraqueza do Projeto de Lei 6.840 está na abordagem. De acordo com os apontamentos da Educação Histórica: só é possível uma aprendizagem histórica significativa quando esta se fizer a partir da Cognição Situada na Racionalidade Epistemológica da História, sendo preferível, portanto, uma organização disciplinar do currículo a uma organização por área do conhecimento (SCHIMIDT, 2009). Por quê? 
Por que do ponto de vista cognitivo a aprendizagem histórica avança qualitativamente quando esta pauta-se nos fundamentos epistemológicos que constroem a ciência da História. Daí a importante articulação entre conceitos de segunda ordem - como inferência, mudança, evidência, narrativa, explicação, plausibilidade entre outros - e os conceitos substantivos - como Revolução Constitucionalista de 1932, Revolução Francesa, Era Vargas, Ditadura Militar e outros. São os conceitos de segunda ordem que dão aos jovens os instrumentos necessários para compreenderem como o conhecimento científico é produzido. Numa organização por área do conhecimento, no que refere-se à aprendizagem histórica, o máximo que a escola poderá oferecer será um rol de conceitos substantivos difusos sobre noções de Constituição Federal. Isso o livro $O$ Estado Nacional e a Constituição de novembro 1937: para uso da juventude já fazia e servia bem às propostas fascistas do Estado Novo. No livro do desembargador Álvaro Berford e no Projeto de Lei 6.840 falta aquilo que Rüsen definiu como a "qualidade histórica da mudança temporal (RÜSEN, p. 93)." Ao organizar o currículo por áreas do conhecimento o Projeto de Lei 6.840 atenta contra a formação de uma consciência histórica em que, nas palavras da professora Maria Auxiliadora Moreira dos Santos Schmidt (2009, p.39).

[...] a relação presente e passado seja fundamentada em narrativas mais complexas, que se prestem a uma orientação temporal para a vida presente, baseadas em princípios como liberdade, democracia e direitos humanos, fundamentos de uma formação para a cidadania.

Outro aspecto fundamental à Cognição Histórica Situada que poderá ser comprometida pelo Projeto de Lei 6.840 está no recurso às investigações dos conhecimentos prévios dos jovens. Essa abordagem vem possibilitando aos professores investigadores, após a categorização das respostas dos jovens educandos, uma seleção mais criteriosa das fontes históricas e estratégias didáticas adequadas ao reconhecimento e possíveis superações das carências de orientação histórica dos sujeitos cognoscentes, ou seja, de professores e alunos.

E finalmente, ao organizar o currículo do Ensino Médio por áreas do conhecimento o PL 6.840 dilui o caráter narrativo da aprendizagem histórica. É por meio da narrativa que a consciência histórica vem à tona. Ela é a operação mental básica à formação da cultura histórica dos cognoscentes. É a competência narrativa que torna a historicidade de algo tão importante como a Constituição Federal em algo significativo à orientação da vida prática dos jovens (SCHMIDT, 2009; RÜSEN, 2011). Orientação histórica é futuro qualificado. Simples assim! 


\section{REFERÊNCIAS}

BERFORD, Álvaro Bittencourt. O estado nacional e a Constituição de novembro de 1937: para uso da juventude brasileira. Rio de Janeiro: DIP, 1944.

BRASIL. Ato Institucional Número 5 de 13 de dezembro de 1968. Disponível em: http://www.planalto.gov.br/ccivil_03/AIT/ait-05-68.htm - Acessado em: 03/05/2015 às 16:31.

BRASIL. Constituição da República dos Estados Unidos do Brasil de 16 de julho de 1934. Disponível em: http://www.planalto.gov.br/ccivil_03/constituicao/Constituicao34.htm - Acessado em: $24 / 11 / 2014$.

BRASIL. Constituição da República Federativa do Brasil de 24 de janeiro de 1967. Disponível em: http://www.planalto.gov.br/ccivil_03/constituicao/Constituicao67.htm - Acessado em: 24/11/2014 às 21:29.

BRASIL. Constituição da República Federativa do Brasil de 05 de outubro de 1988. Disponível em: http://www.planalto.gov.br/ccivil_03/constituicao/Constituicao.htm - Acessado em 13/11/2014 às $16: 10$.

BRASIL. Constituição dos Estados Unidos do Brasil de 10 de novembro de 1937. Disponível em: http://www.planalto.gov.br/ccivil_03/constituicao/Constituicao37.htm - Acessado em: 24/11/2014 às 08:37.

BRASIL. Constituição dos Estados Unidos do Brasil de 18 de setembro de 1946. Disponível em: http://www.planalto.gov.br/ccivil_03/constituicao/constituicao46.htm - Acessado em 03/05/2015 às 16:20.

BRASIL. Emenda Constitucional $n^{0} 1$ de 17 de outubro de 1969. Disponível em: http://www.planalto.gov.br/ccivil_03/constituicao/Emendas/Emc_anterior1988/emc01-69.htm Acessado em: 03/05/215 às 16:27.

BRASIL. Lei $\mathbf{n}^{\mathbf{0}} \mathbf{5 . 6 9 2}$ de 11 de agosto de 1971. Disponível em: http://www.planalto.gov.br/ccivil_03/leis/15692.htm - Acessado em: 29/04/2015 às 14:47.

BRASIL. Lei $\mathbf{n}^{\circ} \mathbf{9 . 3 9 4}$ de 20 de dezembro de 1996. Disponível em: http://www.planalto.gov.br/ccivil_03/leis/19394.htm - Acessado em 29/04/2015 às 14:44.

BRASIL. Lei $\mathbf{n}^{\mathbf{4}} \mathbf{4 . 0 2 4}$ de 20 de dezembro de 1961. Disponível em: http://www.planalto.gov.br/ccivil_03/leis/14024.htm - Acessado em 29/04/2015 as 14:50.

BRASIL. Projeto de Lei $\mathbf{n}^{\mathbf{0}} 6840$ de 2013. Brasília: Câmara dos Deputados/Comissão Especial destinada a promover Estudos e Proposições para a Reformulação do Ensino Médio - CEENSI, 2013. 6840/2013 - Acessado em: 03/05/2015 às 12:18.

CARNEIRO, Moacir Alves. LDB fácil: leitura crítico-compreensiva artigo a artigo. Petrópolis: Vozes, 2014. 
CASTRO, Gabriel; JELIN, Daniel. Marco da redemocratização, Constituição faz 25 anos. Disponível em: http://veja.abril.com.br/noticia/brasil/o-povo-diante-da-lei - Acessado em 09/09/2014.

CASTRO, Gabriel; JELIN, Daniel. O povo diante da lei. In: Veja, edição 2342 , ano 46, n $^{\circ} 41$, 09/10/2013. Disponível em: http://veja.abril.com.br/acervodigital/home.aspx - Acessado em $30 / 08 / 2015$.

DUNCAN, Aryosto. O aniversário da Constituição. In: O Malho, 21/02/1914. Disponível em: http://www.blogdoims.com.br/ims/a-causa-comum-da-alegria-por-elizama-almeida-e-laura-klemz Acessado em: 24/10/2014 às 21:50.

RIBEIRO, Maria Luisa Santos. História da educação brasileira: a organização escolar. Campinas: Autores Associados, 2011.

RÜSEN, Jörn. Aprendizagem histórica: fundamentos e paradigmas. Curitiba: W. A. Editores, 2012.

RÜSEN, Jörn. Reconstrução do passado - Teoria da História II: os princípios da pesquisa histórica. Brasília: Editora Universidade de Brasília, 2007.

SCHMIDT, Maria Auxiliadora. Cognição histórica situada: que aprendizagem histórica é essa? In: SCHMIDT, Maria Auxiliadora; BARCA, Isabel. Aprender história: perspectivas da educação histórica. Ijuí: Ed. Unijuí, 2009.

SCHMIDT, Maria Auxiliadora Moreira dos Santos; BARCA, Isabel; MARTINS, Estevão de Rezende (orgs). Jörn Rüsen e o ensino de História. Curitiba: Editora UFPR, 2011. 